\title{
Assessment of surface wind datasets for estimating offshore wind energy along the Central California Coast
}

\author{
Yi-Hui Wang a, b, *, Ryan K. Walter ${ }^{\text {a, c }}$, Crow White ${ }^{\text {a, b }}$, Hayley Farr ${ }^{\text {b }}$, \\ Benjamin I. Ruttenberg a, b \\ a Center for Coastal Marine Sciences, California Polytechnic State University, San Luis Obispo, CA, USA \\ ${ }^{\mathrm{b}}$ Biological Sciences Department, California Polytechnic State University, San Luis Obispo, CA, USA \\ c Physics Department, California Polytechnic State University, San Luis Obispo, CA, USA
}

\section{A R T I C L E I N F O}

Keywords:

Offshore wind energy

Scatterometers

Reanalyses

Regional atmospheric models

Surface winds

Tradeoff analysis

\begin{abstract}
A B S T R A C T
In the United States, Central California has gained significant interest in offshore wind energy due to its strong winds and proximity to existing grid connections. This study provides a comprehensive evaluation of near-surface wind datasets in this region, including satellite-based observations (QuikSCAT, ASCAT, and CCMP V2.0), reanalysis (NARR and MERRA), and regional atmospheric models (WRF and WIND Toolkit). This work highlights spatiotemporal variations in the performance of the respective datasets in relation to in-situ buoy measurements using error metrics over both seasonal and diurnal time scales. The two scatterometers (QuikSCAT and ASCAT) showed the best overall performance, albeit with significantly less spatial and temporal resolution relative to other datasets. These datasets only slightly outperformed the next best dataset (WIND Toolkit), which has significantly greater temporal and spatial resolution as well as estimates of winds aloft. Considering tradeoffs between spatiotemporal resolution of the underlying datasets, error metrics relative to in-situ measurements, and the availability of data aloft, the WIND Toolkit appears to be the best dataset for this region. The framework and tradeoff analysis this research developed and demonstrated to assess offshore wind datasets can be applied in other regions where offshore wind energy is being considered.
\end{abstract}

\section{Introduction}

Over the last few decades, renewable energy sources have become an increasingly important component of broader energy portfolios. Costs of renewable energy have decreased substantially, and more governments recognize the importance of reducing greenhouse gas emissions. As a result, governments at many levels have set targets for increasing renewable energy generation. For example, across the European Union, the European Parliament and Council has set a target of $20 \%$ for energy consumption from renewables by the year 2020 (2020 Climate \& Energy Package). Additionally, many states within the United States have adopted increased renewable energy portfolio targets. This includes California, which has set a goal to supply $50 \%$ of energy through renewable sources by the year 2030 (SB350-Clean Energy and

\footnotetext{
* Corresponding author. Center for Coastal Marine Sciences, California Poly technic State University, San Luis Obispo, CA, USA.

E-mail address: ywang59@calpoly.edu (Y.-H. Wang).
}

Pollution Reduction Act of 2015).

In response to governmental initiatives and decreases in costs, deployment of renewable energy projects has been increasing rapidly, with an emphasis on photovoltaic solar and land-based wind turbines [1]. Offshore wind turbines also have received considerable interest and investment, particularly in Europe [2]. Offshore wind energy has several advantages over solar and landbased energy sources since offshore winds tend to be stronger and more consistent than land-based winds [3] and are less likely to directly conflict with other land-use activities. Additionally, offshore wind energy production may be able to reduce discrepancies in production and demand that are difficult to alleviate with solar output because of its diurnal cycle.

To best guide the evaluation and planning of offshore wind energy in a particular area, accurate wind datasets with sufficient temporal and spatial resolution are needed. Offshore winds typically exhibit temporal variability on interannual, seasonal, synoptic, and diurnal time scales. Furthermore, wind power is proportional to the cube of the wind speed, meaning that small changes in wind 
speed (e.g., over the course of the day or with different seasons) can lead to drastic differences in power output. Also, for power generation to be most valuable, it will need to match grid demands and base load needs, which vary daily and seasonally. Thus, wind datasets long enough to capture interannual variability and with sufficient temporal resolution to resolve diurnal variability are required for estimating wind energy power production and value. In addition, understanding spatial variation in offshore wind power can help support site planning and assessment by highlighting areas with the greatest potential to generate power and therefore areas with the greatest potential value. Despite the importance of understanding temporal and spatial variations in offshore winds for assessing this renewable energy resource, previous work has rarely resolved both daily and seasonally cycles at multiple sites and/or over a large area. Moreover, the utilization of temporally-averaged (mean) wind speeds over an annual cycle can lead to large errors and mismatches in grid demand and production estimates over shorter (seasonal and daily) time scales.

The lack of detailed assessments across a range of time scales and over broad spatial domains is mainly attributable to the absence of a single perfect offshore wind dataset with the appropriate temporal and spatial resolution. In-situ near-surface wind measurements from moored buoys are often available over long time periods (decades) with a very high temporal resolution (hourly or better), but these buoys are usually sparse (often $>10-100 \mathrm{~km}$ apart). Remote sensing measurements of near-surface winds obtained from satellites equipped with scatterometers can measure vector wind fields across large areas that are more spatially resolved than buoy platforms, but the measurements are only available during satellite passes, at most several times per day [4]. Reanalysis products, which objectively combine both observations and numerical models, often have consistent temporal resolution over decades and contain winds at various vertical levels above the surface, but have coarser spatial resolution compared to satellite-derived data. Finally, regional atmospheric models have some of the highest spatial and temporal resolution, including data aloft at various vertical levels; however, they often experience substantial error relative to in-situ observations and are sensitive to local parameterizations [5].

Previous studies have evaluated the performance of various wind datasets in different regions (see Carvalho et al. [3] and the references therein). Pickett et al. [6] and Tang et al. [7] assessed the performance of QuickSCAT satellite observations relative to local buoys along the West Coast of the United States, but they did not assess other datasets. Carvalho et al. [8] conducted a comprehensive comparison of satellite-based observations, reanalysis products, and the Weather Research and Forecast (WRF) regional model with five buoys in the Iberian Peninsula coast. Carvalho et al. [3] extended the analyses of Carvalho et al. [8] by including newer scatterometers (e.g. ASCAT). However, these studies focused on error metrics over one year and did not consider longer time periods or seasonal and diurnal variability. Alvarez et al. [9] used a longer time period (10 years) to evaluate satellite-based products and reanalysis products against in-situ buoy measurements in the southern Bay of Biscay. They found that QuikSCAT had the lowest bias in wind speed and wind direction and the Cross-Calibrated Multi-Platform (CCMP, blended satellite product) had the lowest error, but they did not include an analysis of the diurnal signal.

Collectively, these studies and others (see Carvalho et al. [3] and the references therein), also suggest that the performance of different wind products varies by study region, indicating the need for site-specific analyses. The majority of site-specific evaluations of offshore wind data have focused on coastal waters along Europe, typically in association with existing or planned offshore wind farms (e.g. Refs. $[3,8-10])$. To date, all but one of the world's offshore wind farms in operation consist of fixed-bottom wind turbines located in shallow waters of less than $100 \mathrm{~m}$. Yet, as technology advances, the cost of building floating wind turbines in water greater than $100 \mathrm{~m}$ deep may be less than that of fixedbottom platforms by 2030 [11]. The first MW-scale floating turbine was successfully deployed in the North Sea in 2009 [45]. In 2017, the world's first floating offshore wind farm was successfully launched with the Hywind project in Scotland, paving the way for future wind farms in deeper waters further from the coast [46]. With improvements in floating turbine technology, deployment of offshore wind farms is likely to increase in the future, particularly in areas with deeper shelf waters. Understanding wind patterns (both spatially and temporally) in these environments will be key to guiding and assessing marine renewable energy production.

Along the West Coast of the United States the continental shelf is narrow, such that waters are often $>100$ m deep only a few kilometers from shore. As a result, the majority of the ocean area with the potential for wind power production is located in deep waters where floating turbines would be necessary [12]. The Central California region considered in this study, spanning from south of Monterey Bay to Point Conception is characterized by moderately strong winds throughout the year (e.g., [13]; Fig. 1). Additionally, this region is located in the vicinity of several existing connections to the state's electrical grid, including the Morro Bay power plant (closed in 2014) and the Diablo Canyon nuclear power plant (California's last remaining nuclear power plant slated to close in 2025). Finally, the study domain is outside of National Marine Sanctuary areas, where restrictions on disturbance to the seabed will likely preclude floating turbine deployment. Attracted by these features, private industry has shown great interest in pursuing permits from government agencies for the development of deep water, floating offshore wind farms (BOEM: https://www.boem.gov/California/). Therefore, a detailed analysis of the available wind products in this region is needed. However, aside from a few simple analyses of winds (e.g. [14]), there are no comprehensive assessments of longrange, high-resolution wind products in this region. Without this information, it is difficult to accurately evaluate the power production potential of this region.

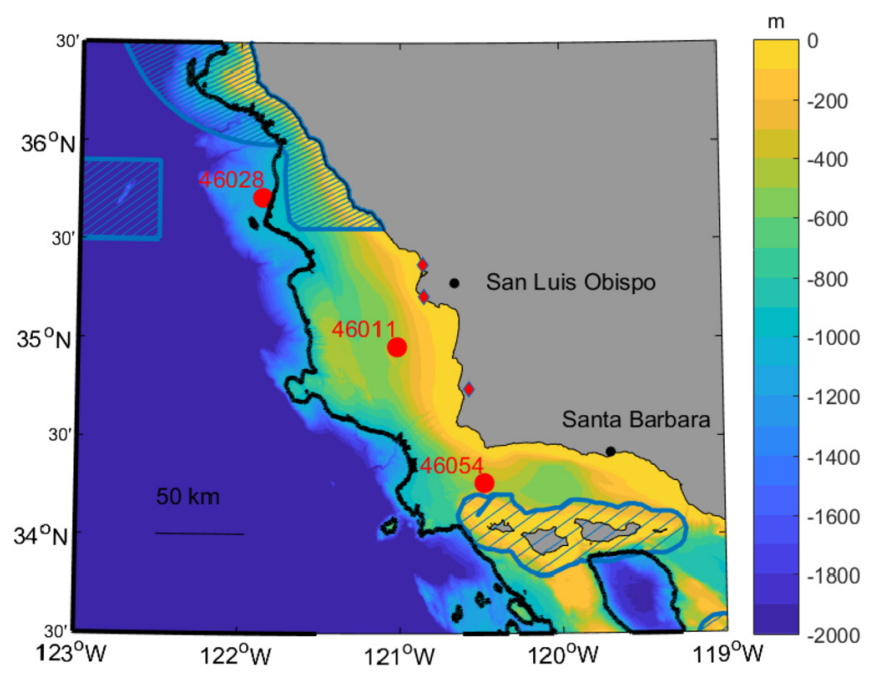

Fig. 1. Bathymetry of the Central California Coast highlighting the locations of buoy platforms (red circles, representing buoys 46028, 46011, 46054 from north to south), existing state electrical grid connections (red diamonds), National Marine Sanctuaries (dashed blue lines; Monterey Bay Sanctuary to the north and Channel Islands Sanctuary to the south), and the $1000 \mathrm{~m}$ isobath (solid black line). The state electrical grid connections from north to south are the Morro Bay power plant, Diablo Canyon nuclear power plant, and Vandenberg Air Force Base. 
To address this knowledge gap, we conducted a comprehensive evaluation of near-surface winds from various datasets (satellitebased, model, reanalysis) and compared them to local buoy measurements. We used these datasets, which span nearly a decade and with up to 2-km spatial resolution, to assess error metrics (bias and root-mean-square-error) over seasonal and diurnal time scales. Using the results of these point-to-point comparisons, and consideration of the spatiotemporal resolution of each dataset and whether it provides data aloft, we examined tradeoffs between various dataset attributes (e.g. bias, error, spatial and temporal resolution, availability of data aloft) to identify the best dataset for offshore wind energy application. We then explored characteristics of the chosen dataset to reveal temporal changes in near-surface wind speeds across the domain along the Central Coast of California. The framework we developed to evaluate the various products is readily applicable to other regions where similar analyses are needed, and the wind dynamics we reveal for the Central Coast can be used to support the generation of accurate and detailed estimates of potential power production in the region.

\section{Data and methods}

\subsection{Study domain}

The Central Coast of California is located along the eastern boundary of the Pacific Ocean and features steeply sloping bathymetry. In this study, we considered the domain bounded by the Monterey Bay National Marine Sanctuary to the north, the Channel Islands National Marine Sanctuary to the south, and the $1000 \mathrm{~m}$ isobath in the offshore direction, generally west (Fig. 1). The offshore limit is the maximum water depth for offshore wind turbine installation based on current technology and industry experience [12]. Along this stretch of coastline, there are three existing connections to the state's electrical grid: the Morro Bay power plant (closed in 2014), the Diablo Canyon nuclear plant (slated to close in 2025), and Vandenberg Air Force Base. This region is characterized by moderately strong and consistently equatorward winds throughout much of the year, particularly for the region north of Point Conception (e.g. $[13,15])$. A previous study suggested that the annual average of wind speed at hub height exceeds $7 \mathrm{~m} \mathrm{~s}^{-1}$, highlighting the potential for offshore wind farms [12].

\subsection{Wind datasets}

\subsubsection{Buoy observations}

Near-surface winds in this study domain were obtained from moored buoys measuring winds at $5 \mathrm{~m}$ above the surface and reporting an average wind speed every $10 \mathrm{~min}$ (i.e., the National Data Buoy Center (NDBC) continuous wind product, http://www. ndbc.noaa.gov/). We employed buoy data as a reference to represent true characteristics of near-surface winds, as is commonly done in the existing literature (e.g. [16]). While buoy measurements are the best available in-situ data, buoy measurements may be less reliable under strong winds [17], but these measurements are still likely the best estimates of true wind speeds. Among all datasets considered, the buoy dataset is the only to output near-surface winds at $5 \mathrm{~m}$ above the sea surface, with the other datasets outputting near-surface winds at $10 \mathrm{~m}$ above the sea surface. Thus, to enable a direct comparison, we converted the buoy-measured wind speeds from $5 \mathrm{~m}$ to $10 \mathrm{~m}$ assuming a neutrally stable atmosphere following the method of Liu and Tang [18]. This is a reasonable assumption given that calculated atmospheric stabilities show a neutrally stable atmosphere during most seasons and hours of the day. Potential errors in $10-\mathrm{m}$ winds speeds when atmospheric stability deviates slightly from neutral conditions are expected to be small [19]. Buoys 46028 and 46011 are located north of Point Conception, and buoy 46054 is located just to the south of Point Conception, at the western edge of the Santa Barbara Channel (red dots in Fig. 1).

\subsubsection{Satellite-based observations}

We evaluated two scatterometers, which measure surface wind stress by sending microwave signals and then recording the backscattered signal in response to ocean roughness (e.g. Ref. [18]). Surface wind stress is converted to equivalent neutral winds $10 \mathrm{~m}$ above grounds based on the assumption of a nearly neutral atmosphere [18]. Vector wind fields are produced at approximately the same geographical location during ascending and descending passes of the satellite (i.e., twice per day). Here, we opted to use the swath data with $12.5 \mathrm{~km}$ spatial resolution because this high resolution product can contain small-scale features [20]. We downloaded both scatterometer-derived datasets from the NASA's Jet Propulsion Laboratory Physical Oceanography Distributed Active Archive Center site (https://podaac.jpl.nasa.gov).

The first scatterometer dataset we evaluated was QuikSCAT, which measures the backscattered signal using the Ku-band frequency and passes through our study domain around 5 and $18 \mathrm{~h}$ every day. QuikSCAT data were available from June 1999 to November 2009. This widely-used product has been validated for accuracy against in-situ buoy observations over various forcing regimes (e.g. [21]). We adopted the latest version of the Level 2 product (QuikSCAT Level 2B Version 3), which uses the improved geophysical model function and corrected rain contaminated wind speeds with a neural network approach [22].

The second scatterometer dataset we evaluated was ASCAT, which is a new-generation scatterometer launched in October 2006. It agrees well with QuikSCAT especially when wind speeds range between $3 \mathrm{~m} \mathrm{~s}^{-1}$ and $20 \mathrm{~m} \mathrm{~s}^{-1}$ [23]. ASCAT passes a local point around 9 and $20 \mathrm{~h}$ and uses the C-band frequency operation, which is less sensitive to rain contamination than the Ku-band frequency operation [24]. Because of its narrower swath width, ASCAT is limited to approximately $60 \%$ of the coverage of QuikSCAT during the same period [25]. The ASCAT Level 2-Coastal product applies a boxcar filtering to yield more wind data close to the coast [26]. We used the Level 2 product's Climate Data Record version, which was reprocessed using consistent calibration from January 2007 to March 2014.

The last satellite-based product we assessed was the CrossCalibrated Multi-Platform Version 2 (CCMP V2.0, a continuation of CCMP Version 1.1) [27]. We obtained this dataset from Remote Sensing Systems (http://www.remss.com/). This blended product combines satellite-derived wind fields from microwave radiometers and scatterometers, with moored buoys and ERA-Interim model data using a Variational Analysis Method. It provides global and gap-free wind fields on a $0.25^{\circ}$ grid four times per day from 1987 to the present. Previous studies in the southern Bay of Biscay [9] and the Iberian Peninsula coast [3,8] demonstrated that CCMP accurately captured offshore winds.

\subsubsection{Reanalysis datasets}

We also assessed two reanalysis products, which combine insitu observations with numerical models: 1) Modern-Era Retrospective Analysis (MERRA, http://disc.sci.gsfc.nasa.gov/mdisc/), a global reanalysis product [28], and 2) North American Regional Reanalysis (NARR, https://www.esrl.noaa.gov/psd/), a regional reanalysis product [29]. MERRA is a commonly-used global reanalysis product for wind resource evaluations (e.g. [30]). It provides hourly data on a grid of $2 / 3^{\circ}$ by $1 / 2^{\circ}$ from 1979 to 2016. NARR outputs data every $3 \mathrm{~h}$ (since 1979) and has a spatial resolution of $32 \mathrm{~km}$. Both products yield wind data at various pressure levels 
above the surface. In part because it assimilates more observations into its model, NARR data yield more accurate results relative to global reanalysis products [29]. Previous studies in other regions have also shown good agreement between NARR and in-situ measurements near the surface and aloft (e.g. [31-33]).

\subsubsection{Regional atmospheric model simulations}

We analyzed simulated near-surface wind speeds from two regional model datasets. The first dataset covers the entire U.S. West Coast and was carried out using WRF model version 3.6 [34,35], which is initialized and forced at boundaries with the Climate Forecast System Reanalysis. The model is configured with two nested grids, where the outer domain has a horizontal resolution of $18 \mathrm{~km}$, and the inner domain has a resolution of $6 \mathrm{~km}$. It is set up with a full set of parameterization schemes including the Mellor-Yamada-Nakanishi-Niino planetary boundary layer scheme [36], which is one of the best planetary boundary layer schemes to simulate realistic cloud cover and wind. More details can be found in Renault et al. [35]. Hourly 10-m wind fields above the ground level are available from 2004 to 2013 and used for this study.

The second regional model dataset is from the WIND Toolkit (https://www.nrel.gov/grid/wind-toolkit.html), developed by the National Renewable Energy Laboratory (NREL) for the purpose of wind power application [30]. The results were generated by the WRF model version 3.4.1, which is initialized and forced at boundaries by the European Center for Medium-Range Weather Forecasts Interim Reanalysis. This model uses three nested grids with resolutions of $18 \mathrm{~km}, 6 \mathrm{~km}$, and $2 \mathrm{~km}$, respectively, with the inner $2 \mathrm{~km}$ grid covering the entire contiguous United States. The optimal model configuration is the best one from the eight model configurations tested by NREL. This configuration outputs simulations with small overall bias and in complex terrain, realistic hourly and diurnal wind variations, and highly resolved wind fields near the surface. More details can be found in Draxl et al. [30,37]. We analyzed hourly $10-\mathrm{m}$ wind fields (2007-2013). In addition to nearsurface wind fields, wind data at higher altitudes up to $200 \mathrm{~m}$ are also available.

\subsection{Comparisons and statistics}

In order to compare the various datasets to the buoy observations, we obtained the closest point in space and time from each wind dataset relative to each of the three buoys. We included observations only if they met our collocation criteria with buoy data: measurements must have been recorded within $30 \mathrm{~min}$ of a buoy measurement and no more than $12.5-\mathrm{km}$ from the buoy for all datasets except WIND Toolkit. We use a more restrictive spatial criterion of $2 \mathrm{~km}$ for WIND Toolkit because of its higher resolution of $2 \mathrm{~km}$. Unlike gridded datasets, the closest swath point of the scatterometer data to a local buoy is not fixed and its measurement time is slightly different each day. In line with previous studies (e.g. [6]), we found no connection between the separation distance and the bias in QuikSCAT/ASCAT relative to a local buoy. Between 2000 and 2008 (time period used for comparison in this study), the mean separation distance between the closest QuikSCAT point and buoy was 5.59, 4.45, and $4.93 \mathrm{~km}$ for buoy sites 46028, 46011, and 46054, respectively. Between 2007 and 2013, the mean separation distance between the closest ASCAT point and buoy was 4.91, 3.55, and $3.77 \mathrm{~km}$. The distance between a local buoy and the closest point of a comparative gridded dataset is shown in Table 2.

We evaluated the seven aforementioned wind datasets in relation to buoy measurements using the collocation criteria described above. To summarize the performance of each wind data, we utilized the statistical metrics of the bias and the root-mean-squareerror (RMSE) between one dataset and buoy measurements. To illustrate the relationship between two variables, we fitted the paired data to a linear regression line and provided its intercept, its slope, and the coefficient of determination $\left(R^{2}\right)$ of the model fit in Tables 2-4.

Complete annual data were available for at least 7 years for all datasets (see Table 1 for details), thereby reducing the impact of interannual variability on our analysis. To display climatological characteristics of near-surface winds, we used buoy data from 1998 to 2016 and compared these winds between the buoys and other datasets for each year of overlap.

\subsection{Tradeoff analysis}

In order to evaluate the relative merits of the datasets and identify the best dataset for offshore wind power applications, we applied a tradeoff analysis to our results. Tradeoff analysis is a useful graphical tool for comparing the relative performance of a set of options in relation to multiple objectives [38]. We considered five key objectives, or factors, in the tradeoff analysis of the seven wind datasets: temporal and spatial resolution (higher better), the absolute value of bias and RMSE (lower better), and availability of wind speed data aloft (better). We then conducted visual inspection of pairwise tradeoff plots of the seven datasets in relation to the five factors in order to compare and contrast the relative merits of the datasets and identify the most appropriate one(s) for offshore wind power applications.

\section{Results}

\subsection{Buoy climatology}

Climatological characteristics of buoy winds are shown in Fig. 2. Each curve represents the composite day average wind speed for a particular month (i.e., average wind speed calculated using data over all years from a particular hour during each month). All times referenced are Pacific Standard Time (PST).

The three different buoy sites display similar diurnal structure with daily minimums in the late morning and peaks in the early evening (Fig. 2). There is also a slight seasonality in both the timing of the daily minimums and peaks, as well as the daily range. During months with stronger wind forcing (e.g., spring/summer upwelling months, cf. Walter et al. [15]), the daily peaks arrived slightly later compared to during other months. For example, at 46028, wind speed peaks around $20 \mathrm{~h}$ in May and at $18 \mathrm{~h}$ in January. Notably, the diurnal variability is comparable to that of the seasonal variability. There is also considerable buoy-to-buoy (i.e., spatial) variability at various time scales. Among the three sites, buoy 46054 displayed the strongest diurnal variations in wind speed with differences as large as $3 \mathrm{~m} \mathrm{~s}^{-1}$ between the daily minimum and maximum in some months.

Seasonal cycles also varied among buoys. The $10-\mathrm{m}$ wind speeds at buoys 46028 and 46011 reached their maxima in spring, whereas the $10-\mathrm{m}$ wind speed at buoy 46054 reached its maximum in the summer (see Walter et al. [15] for a discussion of the seasonality at buoy 46011). This seasonal variation is closely connected to largescale pressure systems, which fluctuate seasonally, but tend to produce equatorward winds near the surface along the coastline (see Fewings et al. [13] for a detailed description). Among the three sites, buoy 46054 had the strongest and most variable winds, which is strongly impacted by the interaction between the marine boundary layer and coastal capes (i.e., Point Conception) [13].

\subsection{Paired comparisons with buoy measurements}

Direct comparison between the wind speed calculated from 
Table 1

Characteristics of wind datasets considered for comparison with buoy observations.

\begin{tabular}{|c|c|c|c|c|}
\hline Dataset & Type of dataset & Spatial resolution & Temporal resolution & Time used in this study \\
\hline QuikSCAT & Satellite (Swath) & $12.5 \mathrm{~km}$ & 2 times per day & $2000-2008$ \\
\hline ASCAT & Satellite (Swath) & $12.5 \mathrm{~km}$ & 2 times per day & $2007-2013$ \\
\hline CCMP V2 & Satellites and analyses & $0.25^{\circ}$ lat/lon & 4 times per day & 2004-2013 \\
\hline NARR & Regional reanalysis & $32 \mathrm{~km}$ & 8 times per day & 2004-2013 \\
\hline MERRA & Global reanalysis & $1 / 2^{\circ}$ lat $-2 / 3^{\circ}$ lon & Hourly & 2004-2013 \\
\hline WRF & Regional model & $6 \mathrm{~km}$ & Hourly & 2004-2013 \\
\hline WIND Toolkit & Regional model & $2 \mathrm{~km}$ & Hourly & $2007-2013$ \\
\hline
\end{tabular}

Table 2

Statistical metrics from the linear regression between buoy data and each of the comparison datasets.

\begin{tabular}{|c|c|c|c|c|c|c|}
\hline Buoy & Dataset & Slope & Intercept & $\mathrm{R}^{2}$ & Distance from buoy $(\mathrm{km})$ & Number of valid pairs \\
\hline \multirow[t]{7}{*}{46028} & QuikSCAT & 0.90 & 1.01 & 0.92 & 5.59 & 5654 \\
\hline & ASCAT & 0.94 & 0.25 & 0.94 & 4.91 & 2153 \\
\hline & CCMP V2 & 0.68 & 1.37 & 0.77 & 9.80 & 13013 \\
\hline & NARR & 0.76 & 1.59 & 0.75 & 9.07 & 26018 \\
\hline & MERRA & 0.59 & 1.69 & 0.74 & 26.85 & 78014 \\
\hline & WRF & 0.38 & 4.88 & 0.15 & 3.64 & 78012 \\
\hline & WIND & 0.79 & 1.13 & 0.83 & 0.62 & 55957 \\
\hline \multirow[t]{7}{*}{46011} & QuikSCAT & 0.85 & 1.56 & 0.84 & 4.45 & 5449 \\
\hline & ASCAT & 0.89 & 1.02 & 0.84 & 3.55 & 2241 \\
\hline & CCMP V2 & 0.75 & 2.00 & 0.67 & 13.22 & 12368 \\
\hline & NARR & 0.72 & 1.40 & 0.69 & 7.62 & 24695 \\
\hline & MERRA & 0.62 & 2.04 & 0.64 & 29.07 & 74049 \\
\hline & WRF & 0.39 & 4.77 & 0.14 & 3.24 & 74046 \\
\hline & WIND & 0.77 & 1.65 & 0.73 & 0.89 & 51953 \\
\hline \multirow[t]{7}{*}{46054} & QuikSCAT & 0.68 & 2.23 & 0.82 & 4.93 & 3875 \\
\hline & ASCAT & 0.81 & 1.16 & 0.88 & 3.77 & 1670 \\
\hline & CCMP V2 & 0.53 & 1.66 & 0.62 & 15.41 & 7928 \\
\hline & NARR & 0.49 & 1.13 & 0.53 & 7.62 & 15754 \\
\hline & MERRA & 0.40 & 1.76 & 0.58 & 31.41 & 47392 \\
\hline & WRF & 0.37 & 4.91 & 0.16 & 2.10 & 47385 \\
\hline & WIND & 0.80 & 1.45 & 0.79 & 0.99 & 34001 \\
\hline
\end{tabular}

Table 3

Statistics from the comparison between the buoy data and comparison datasets, including error metrics (bias and RMSE), as well as outputs (slope, intercept, coefficient of determination) from the linear regression between the wind speed difference and the buoy wind speed.

\begin{tabular}{lllllll}
\hline Buoy & Dataset & Bias & RMSE & Slope & Intercept & $\mathrm{R}^{2}$ \\
\hline 46028 & QuikSCAT & 0.26 & 1.22 & -0.10 & 1.01 & 0.12 \\
& ASCAT & -0.18 & 1.03 & -0.06 & 0.25 & 0.06 \\
& CCMP V2 & -0.94 & 2.20 & -0.32 & 1.37 & 0.42 \\
& NARR & -0.15 & 2.03 & -0.24 & 1.59 & 0.23 \\
& MERRA & -1.28 & 2.54 & -0.41 & 1.69 & 0.58 \\
& WRF & 0.41 & 4.47 & -0.62 & 4.88 & 0.32 \\
& WIND & -0.43 & 1.76 & -0.21 & 1.13 & 0.26 \\
46011 & QuikSCAT & 0.67 & 1.50 & -0.15 & 1.56 & 0.14 \\
& ASCAT & 0.38 & 1.40 & -0.11 & 1.02 & 0.08 \\
& CCMP V2 & 0.52 & 2.02 & -0.25 & 2.00 & 0.19 \\
& NARR & -0.29 & 1.90 & -0.28 & 1.40 & 0.26 \\
& MERRA & -0.21 & 2.04 & -0.38 & 2.04 & 0.40 \\
& WRF & 1.17 & 4.07 & -0.61 & 4.77 & 0.28 \\
& WIND & 0.28 & 1.82 & -0.23 & 1.65 & 0.18 \\
46054 & QuikSCAT & -0.49 & 2.03 & -0.32 & 2.23 & 0.50 \\
& ASCAT & -0.33 & 1.47 & -0.19 & 1.16 & 0.31 \\
& CCMP V2 & -1.99 & 3.29 & -0.47 & 1.66 & 0.57 \\
& NARR & -2.78 & 4.00 & -0.51 & 1.13 & 0.55 \\
& MERRA & -2.87 & 4.08 & -0.60 & 1.76 & 0.75 \\
& WRF & 0.04 & 4.43 & -0.63 & 4.91 & 0.36 \\
& WIND & -0.07 & 1.90 & -0.20 & 1.45 & 0.19 \\
\hline
\end{tabular}

each buoy at each site and each respective dataset were made using all data available over the selected time period for all points in each dataset that met collocation criteria. Fig. 3 shows scatter plots and the linear regression line between each wind product's wind speed and the buoy site's wind speed. Statistics from the linear regression
Table 4

Statistical metrics of wind direction $\left(^{\circ}\right)$ from paired data. A positive bias indicates a clockwise bias.

\begin{tabular}{llll}
\hline Buoy & Dataset & Bias & RMSE \\
\hline 46028 & QuikSCAT & 6.74 & 38.74 \\
& ASCAT & 1.49 & 37.36 \\
& CCMP V2 & 6.51 & 41.86 \\
NARR & 3.77 & 40.85 \\
MERRA & 5.95 & 41.98 \\
& WRF & 7.10 & 68.88 \\
WIND & 3.84 & 36.76 \\
46011 & QuikSCAT & 0.44 & 45.83 \\
& ASCAT & -3.09 & 47.30 \\
& CCMP V2 & 2.02 & 44.47 \\
& NARR & 0.26 & 41.96 \\
& MERRA & 0.28 & 44.49 \\
& WRF & 14.50 & 68.05 \\
& WIND & 0.99 & 39.97 \\
46054 & QuikSCAT & 1.39 & 46.85 \\
& ASCAT & -3.86 & 46.73 \\
& CCMP V2 & 7.78 & 42.85 \\
& NARR & -8.32 & 45.03 \\
& MERRA & 11.12 & 45.30 \\
& WRF & 14.18 & 69.37 \\
& WIND & 2.70 & 38.65 \\
\hline
\end{tabular}

and collocation criteria are shown in Table 2. The error metrics (bias and RMSE) are displayed in Table 3.

Based on the performance of the linear regression (Table 2, Fig. 3) and the error metrics (Table 3), ASCAT had the lowest bias and RMSE, and the largest coefficient of regression with buoy-based site measurements, slightly outperforming the other scatterometer-based observation, QuikSCAT. This is not surprising, 


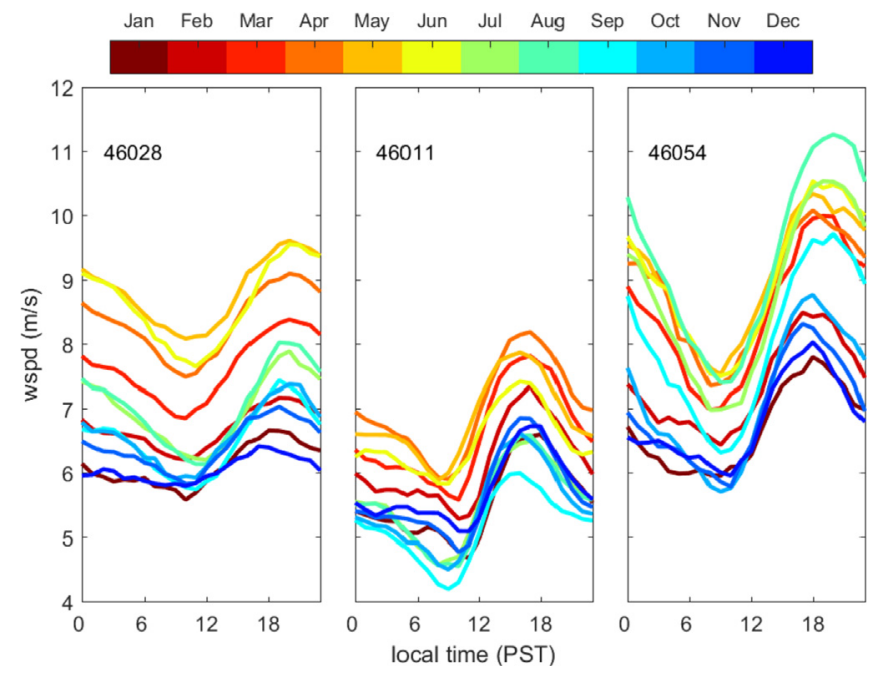

Fig. 2. Composite day average buoy wind speed for a particular month (colors) using data calculated over all years (1998-2016) for each buoy (46028, 46011, and 46054 from left to right).

given previous validations of the product in other regions (e.g. [3]). We note, however, that the scatterometers (particularly ASCAT) have the smallest number of points used for comparison with the buoy data because of the temporal resolution (typically only two measurements per day) and a shorter time period relative to other datasets. Following scatterometer-based observations, the WIND Toolkit showed the best correspondence with buoy data; this dataset even outperformed the scatterometers slightly with respect to bias at buoys 46011 and 46054 and had relatively low error as well (Table 3). We note that the WIND Toolkit is also the most spatially $(2 \mathrm{~km})$ and temporally $(1 \mathrm{~h})$ resolved dataset, and it contains wind data at various levels about the sea surface. While the WIND Toolkit, a version of the WRF regional model, displayed some of the best results, the other WRF model considered (denoted WRF here, a model developed for the West Coast of the United States) showed the worst correspondence to local buoys in this region. Given the sensitivity of the performance of the WRF model in wind simulation to various configurations and parameterizations, (e.g. [5]), it is possible that the better performance of the WIND Toolkit than its counterparts is associated with its configuration particularly optimized for simulating wind for wind energy applications. The largest error (RMSE) among the three sites is generally found at buoy 46054, which is located just south of Point Conception, highlighting the difficulty of resolving the wind field near complex land topography. Among these seven wind datasets, five (ASCAT, QuikSCAT, CCMP, NARR, and MERRA) display the worst correspondence at buoy 46054, while model simulations (WRF and WIND Toolkit) show relatively consistent correspondence across all buoys. The greater biases in the reanalysis datasets at buoy 46054 are likely due to their coarser spatial resolution, which is not able to accurately capture small-scale coastal orography near Point Conception and its impact on the velocity field.

To further investigate the differences between the various datasets and the local buoys, we examined the wind speed difference between a particular dataset and the local buoy as a function of the buoy wind speed (Fig. 4). In general, data products overestimated winds relative to the buoy at low wind speeds and underestimated at high wind speeds, with varying degrees of magnitude. This feature and negative relationship is consistent with the findings of previous studies using less than two years of data $[3,6,7]$. Statistics of the linear regression between wind speed

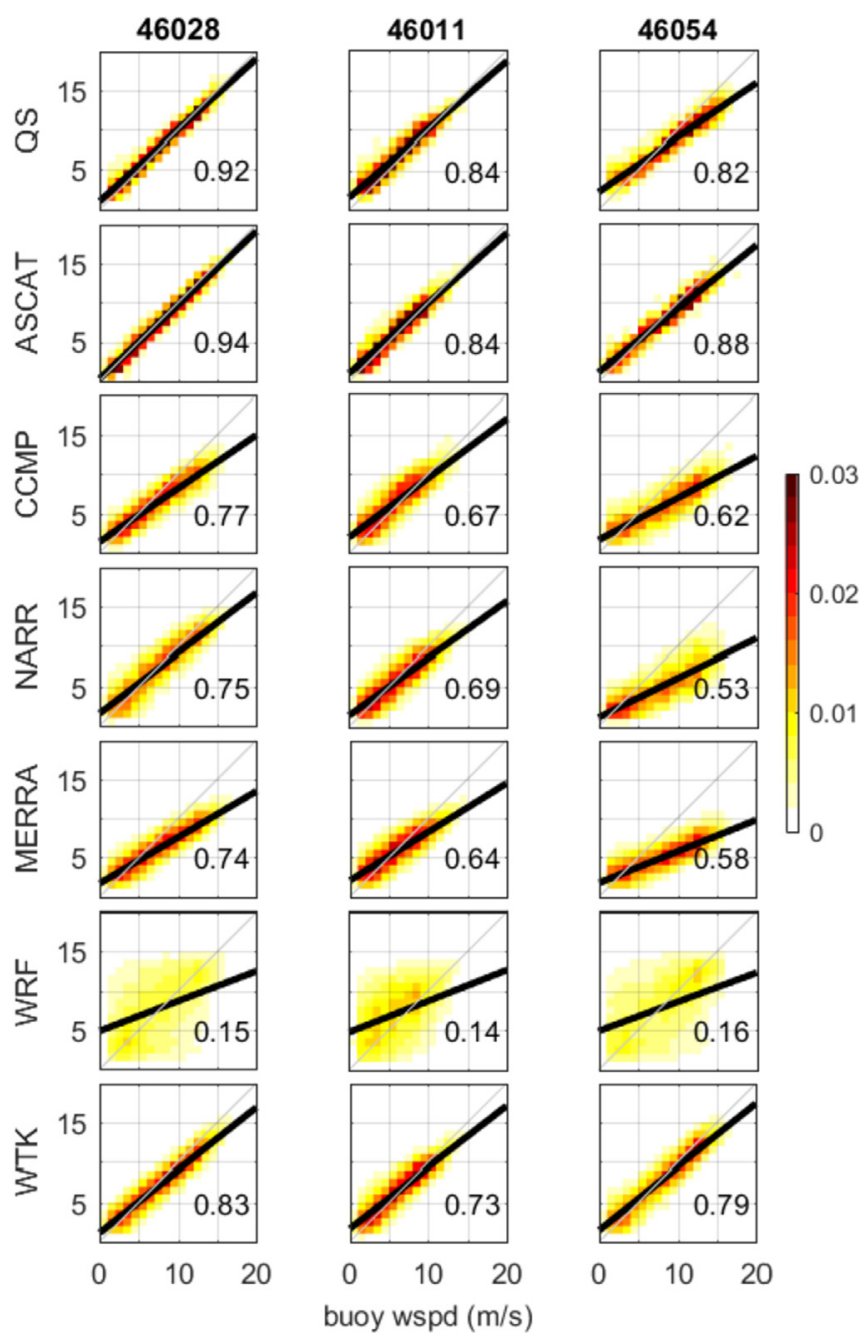

Fig. 3. Comparisons of wind speed between the buoy measurements and each respective dataset (all in $\mathrm{m} \mathrm{s}^{-1}$ ). The value on each subplot shows the coefficient of determination $\left(\mathrm{R}^{2}\right)$ from a linear regression model (fit shown as bold black line). The one-to-one line is also shown for reference (thin gray line). Wind speed is binned by $1 \mathrm{~m} \mathrm{~s}^{-1}$ along both of the $\mathrm{x}$-axis and $\mathrm{y}$-axis, and then divided by the total number of data pairs to yield the frequency of data points in a particular bin (colors). The rows from the top to the bottom are QuikSCAT (QS), ASCAT, CCMP V2.0 (CCMP), NARR, MERRA, WRF, and WIND Toolkit (WTK). The columns from the left to the right represent the local buoy 46028,46011 , and 46054 , respectively. Note that the time period used for analysis depends on data availability.

difference and buoy wind speed are shown in Table 3. Both scatterometer-based observations (ASCAT and QuikSCAT) and WIND Toolkit exhibit smaller slopes among the three local buoys, indicating less functional dependence of the errors on wind speed relative to other datasets. We note that at the lowest and highest wind speeds, wind speed differences are less important for estimating wind power production due to turbine mechanical constraints that require cut-in and cut-out wind speed restrictions at low and high wind speeds, respectively.

\subsection{Seasonal and diurnal bias}

We examined the diurnal and seasonal dependence of bias and error (RMSE) as a function of both the time of day (i.e., diurnal signal) and month (i.e., seasonal signal) (bias: Fig. 5; RMSE: Fig. 6). To ensure that one dataset and reference buoy have the same sample size, we used paired data for the comparison analysis from 


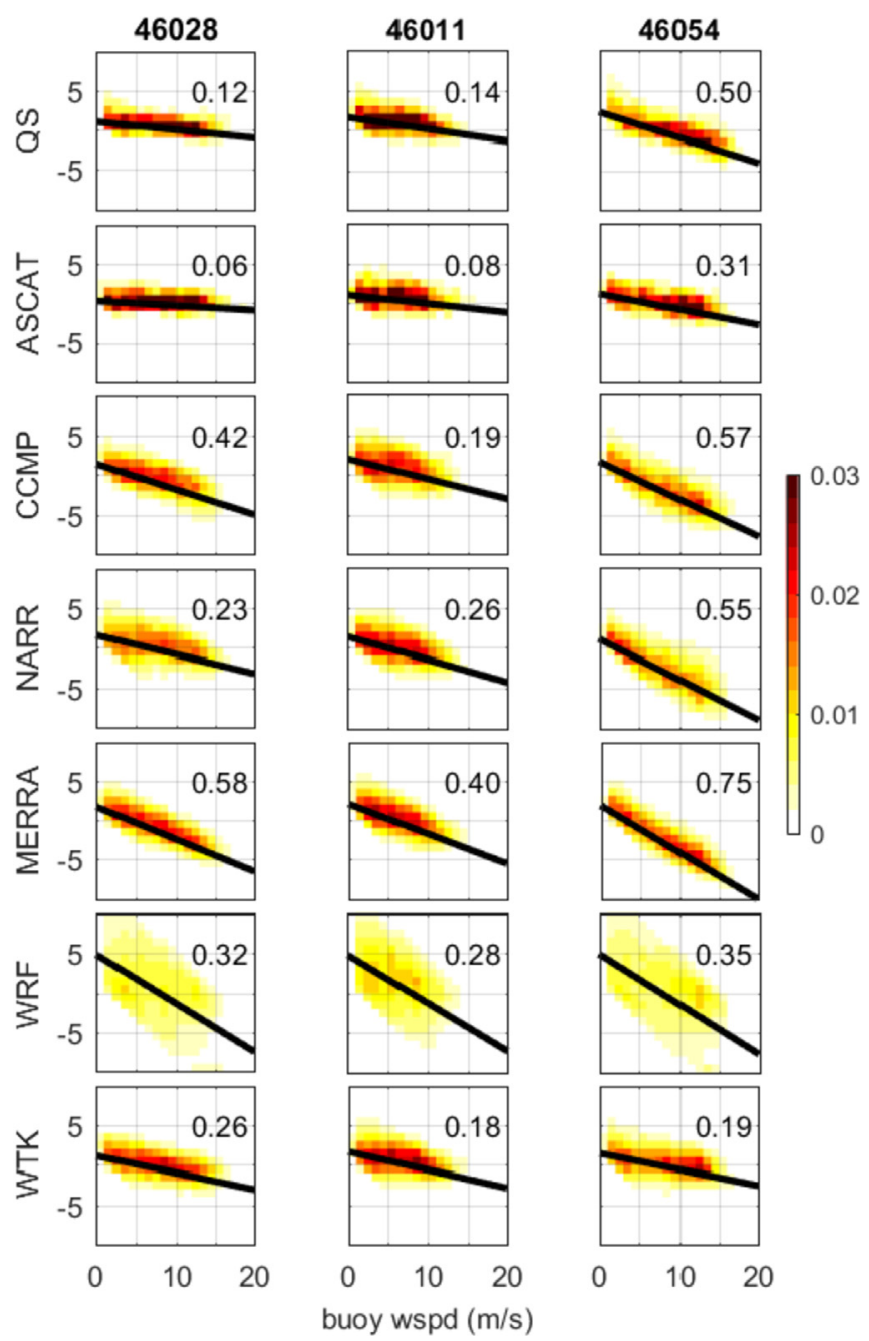

Fig. 4. Differences in wind speed between the buoy and the other respective datasets as a function of the buoy wind speed (all in $\mathrm{m} \mathrm{s}^{-1}$ ). The value on each subplot shows the coefficient of determination $\left(\mathrm{R}^{2}\right)$ from a linear regression model (black line). Wind speed is binned by $1 \mathrm{~m} \mathrm{~s}^{-1}$ along both of the $\mathrm{x}$-axis and the $\mathrm{y}$-axis, and then divided by the total number of data pairs to yield the frequency of data points in a particular bin (colors). The rows from the top to the bottom are QuikSCAT (QS), ASCAT, CCMP V2.0 (CCMP), NARR, MERRA, WRF, and WIND Toolkit (WTK). The columns from the left to the right represent the local buoy 46028, 46011, and 46054, respectively. Note that the time period used for analysis depends on data availability.

Section 3.2. Here, a positive (negative) bias indicates that the respective dataset overestimates (underestimates) the buoy wind speed.

Overall, QuikSCAT and ASCAT show some of the smallest biases among the datasets, although there are only two hours per day for comparison. Generally, both datasets show different performance between the early morning and evening. While the bias is consistently low at 46028 , the bias at 46011 is more positive in the mornings, whereas the bias at 46054 is negative in the evenings. The other satellite-based product, CCMP, is more temporally resolved (6 h resolution), but shows much higher bias. Similar to QuikSCAT and ASCAT, CCMP tends to overestimate buoy-measured wind speeds near 46011. In contrast to 46011, CCMP underestimates wind speeds near 46028 and 46054.

The reanalysis product NARR exhibits consistently low biases at 46028 and 46011, yet strongly underestimates wind speed (i.e., negative bias) at 46054 . Such low and homogeneous biases at the two northernmost buoy sites (46028 and 46011) are not seen in the

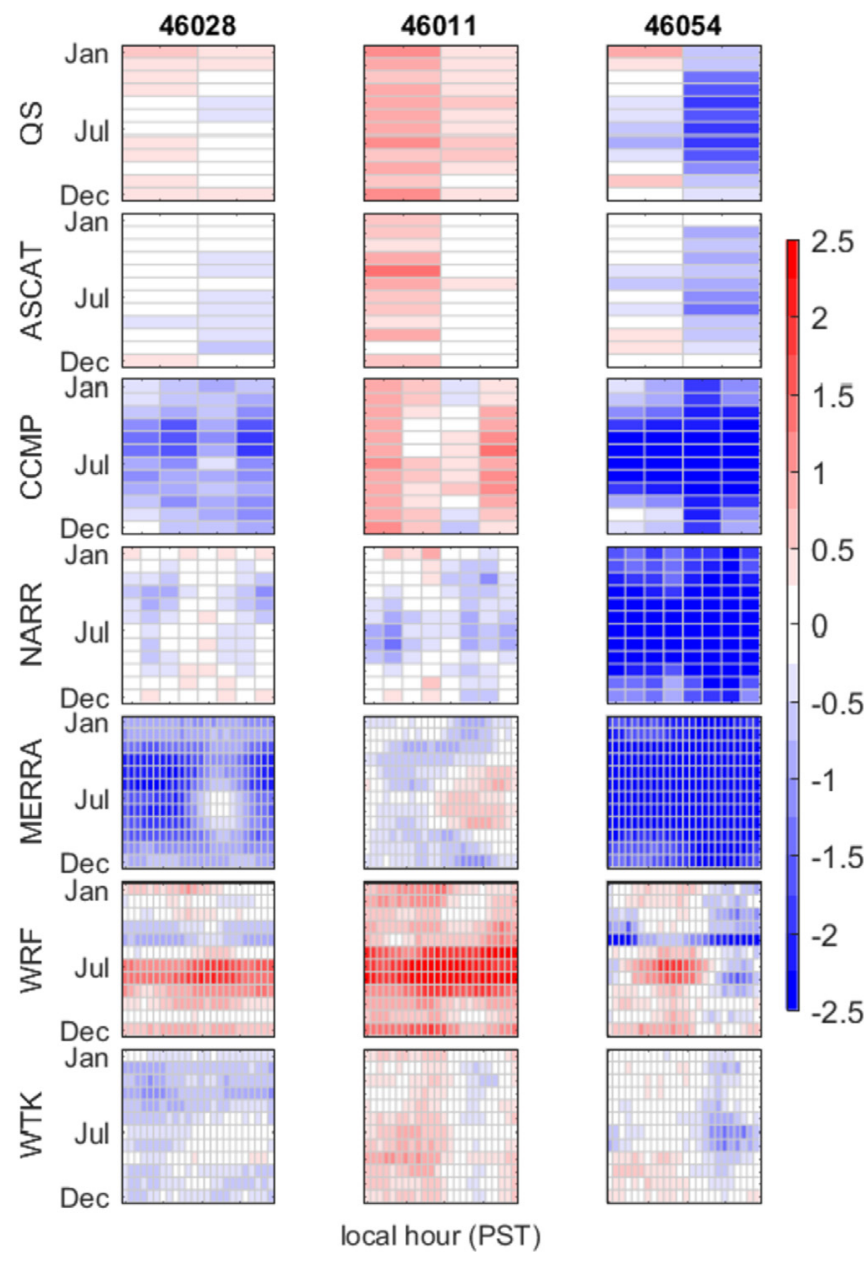

Fig. 5. Bias $\left(\mathrm{m} \mathrm{s}^{-1}\right)$ in the hourly near-surface wind speed in each month for all available paired data in relation to the buoy measurements at 46028 (left), 46011 (middle), and 46054 (right). A positive (negative) bias indicates that the respective dataset overestimates (underestimates) the buoy wind speed. The white color indicates zero bias. The rows from the top to the bottom are QuikSCAT (QS), ASCAT, CCMP V2.0 (CCMP), NARR, MERRA, WRF, and WIND Toolkit (WTK). The following hours (in PST) are shown for the respective dataset: QS (05 and 18); ASCAT (9 and 20); CCMP $(04,10,16$, and 22); NARR $(01,04,07,10,13,16,19$, and 22); and for MERRA, WRF, and WTF (hourly from 00 to 23). See Table 1 for the time period used for analysis of individual datasets.

other reanalysis product, MERRA, which displays weaker wind speeds compared to buoy measurements (i.e., negative bias) in the morning. The weaker winds in the morning, along with no difference (46028) or relatively higher wind speeds (46011) in the evening, particularly from May to September, lead to stronger predicted diurnal cycles than observed at the buoys.

Both atmospheric regional model simulations used in this study display lower biases at 46054 , compared to other datasets. At 46028 and 46011, WRF overestimates wind speed throughout the day in summer months. For the WIND Toolkit, wind speed is underestimated (i.e., negative bias) close to buoy measurements at 46028. It tends to overestimate wind speed (i.e., positive bias) from 00:00 to 12:00 PST at 46011 in contrast to slight underestimates in the evening.

Overall, QuikSCAT, ASCAT, and WIND Toolkit are the best performing datasets with the lowest bias, and hence smallest discrepancies from local buoys. The bias appears to be tied to the RMSE in which the greater bias corresponds to the greater RMSE. Since the diurnal and seasonal patterns in bias (RMSE) are different across the three buoys, a simple correction of the underlying 


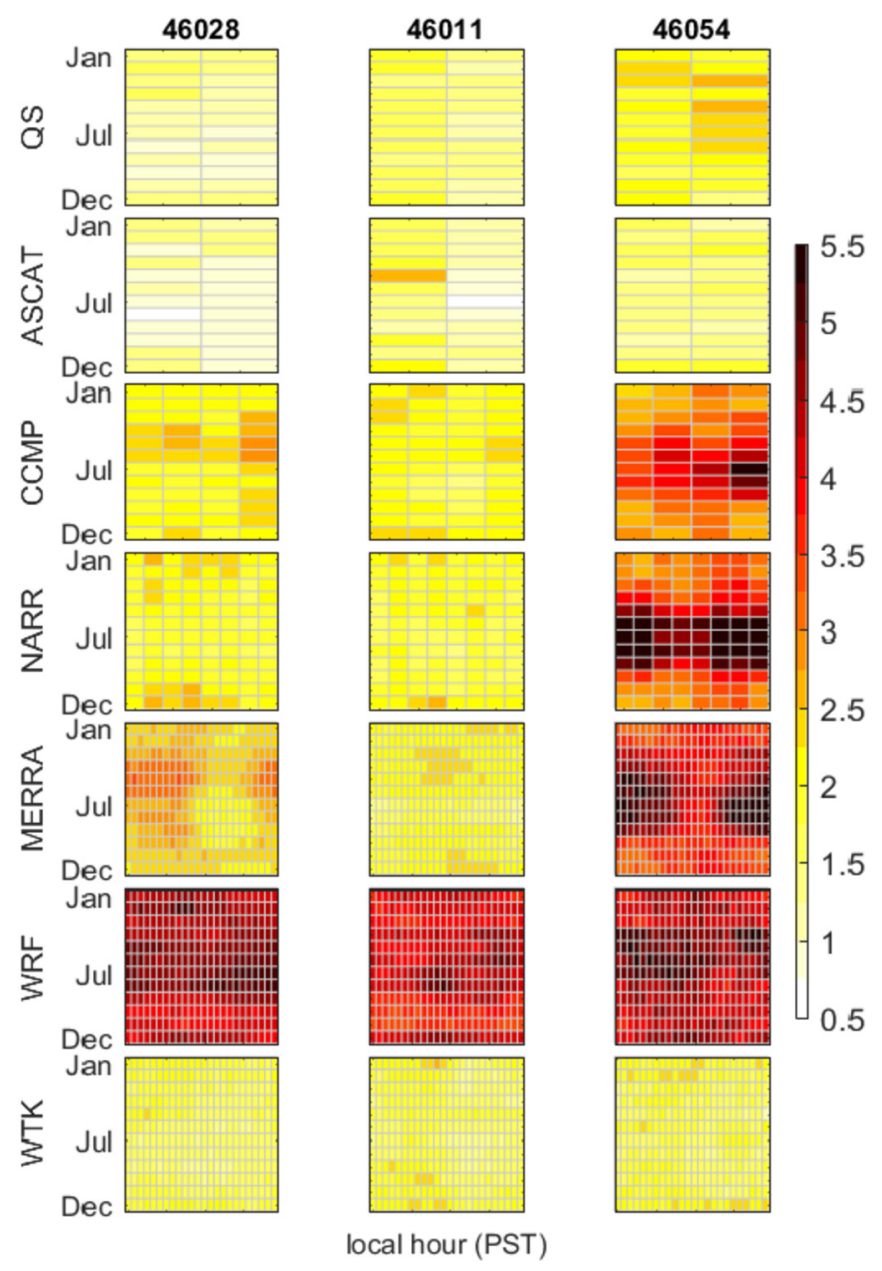

Fig. 6. Similar to Fig. 5, but for root-mean-squared error in the hourly near-surface wind speed in each month $\left(\mathrm{m} \mathrm{s}^{-1}\right)$.

dataset is likely to lead to more uncertainties spatially.

\subsection{Tradeoff analysis for seven datasets}

Although scatterometer-based observations were the best performing datasets relative to buoy measurements in this study domain, their temporal resolution is too coarse to fully resolve the diurnal cycle of near-surface winds. By contrast, the next performing dataset, WIND Toolkit, provides hourly wind fields with much higher spatial resolution. To evaluate the relative merits of the datasets and identify the best dataset for offshore wind power applications, we conducted tradeoff analysis to illustrate important differences in the characteristics of the seven datasets in relation to five factors: the absolute value of bias, RMSE, data availability aloft, temporal resolution, and spatial resolution. Here, we considered the overall performance (the absolute value of bias and RMSE) at the three local buoy sites in this domain (Table 3), but the performance at individual sites can be obtained in a similar fashion.

Fig. 7a shows the mean bias and RMSE over the three buoy sites along with error bars representing one standard deviation from the mean. ASCAT, QuickScat, and WIND Toolkit all have similarly low levels of bias and RMSE, consistently at the three buoy sites; however, among these datasets, only WIND Toolkit contains data aloft (Fig. 7a). Furthermore, WIND Toolkit contains a far superior spatial and temporal resolution, compared with ASCAT and QuickScat (Fig. 7b). Only WRF contains spatial and temporal resolution comparable with that by the WIND Toolkit, but WRF is otherwise inferior because it has a much larger RMSE. Collectively, these tradeoff analysis results indicate that WIND Toolkit is the most appropriate dataset for supporting offshore wind power applications in this region.

\subsection{Spatial and temporal variations of wind speed over a wide area}

Based on the point-to-point comparison and the tradeoff analysis, the WIND Toolkit appears to be the best dataset for offshore wind power applications and can better estimate wind speeds daily and seasonally over a wide area. Fig. 8 displays the average $10-\mathrm{m}$ wind speeds at different hours and over four seasons from 2007 to 2013 using WIND Toolkit. Similar to the three buoy sites, other areas across the central California region are characterized by strong diurnal (weaker in the morning and stronger in the evening) and seasonal (stronger in spring and weaker in fall) variability in the wind speed. The diurnal cycle is enhanced during spring and summer months, relative to fall and winter months, consistent with data from the three buoy sites shown in Fig. 2. Fig. 8 also highlights the local maxima of wind speed near the complex topography of Point Conception.

\subsection{Characteristics of wind direction}

We also assessed the climatology of near-surface wind direction at the local buoys and in comparison with the other wind datasets. We present wind direction in terms of where the wind is coming from in degrees clockwise from true north (i.e., $0^{\circ}$ wind direction indicates a wind coming from the north and blowing to the south). To account for the direction difference due to the discontinuity between $0^{\circ}$ and $360^{\circ}$, and to quantify the direction difference between $-180^{\circ}$ and $180^{\circ}$, the wind direction from the respective data set $\left(\theta_{\mathrm{O}}\right)$ relative to the buoy data $\left(\theta_{\mathrm{B}}\right)$ was modified following Pensieri et al. [16]. First, we computed the wind direction difference $\left(\theta_{\mathrm{O}}-\theta_{\mathrm{B}}\right)$. When $\theta_{\mathrm{O}}-\theta_{\mathrm{B}}>180^{\circ}, \theta_{\mathrm{O}}=\theta_{\mathrm{O}}-360^{\circ}$ and when $\theta_{\mathrm{O}}-$ $\theta_{\mathrm{B}}<-180^{\circ}, \theta_{\mathrm{O}}=\theta_{\mathrm{O}}+360^{\circ}$. With the modified $\theta_{\mathrm{O}}$, the wind speed difference was calculated as $\theta_{\mathrm{O}}-\theta_{\mathrm{B}}$.

Based on the time period of 1998-2016, winds measured at the three buoys are predominately northwesterly (i.e., along-shore equatorward) (see wind rose histograms in Fig. 9). Persistent, but variable in magnitude, northwesterly winds are closely linked to large-scale pressure systems and the interaction between air flows and topography along the coast (e.g. [13]). At the site 46054, nearsurface winds have more westerly components than the other two sites, resulting from steering by the adjacent coastline that is oriented in the E-W direction near the Santa Barbara Channel. Examination of the diurnal cycle shows a more northerly component in the early morning, followed by a more westerly component in the afternoon (not shown), consistent with local sea breezes along the Central Coast (e.g. [39]).

The error metrics (bias and RMSE) of wind direction from paired data are shown in Table 4. Most of the datasets reveal a positive (i.e., clockwise) bias, with the exception of ASCAT at 46011 and 46054 and NARR at 46054 . Similar to the wind speed analysis, the two scatterometers (QuikSCAT and ASCAT) and WIND Toolkit display the best overall performance in terms of bias and RMSE for wind direction. QuikSCAT has the lowest bias in wind direction at 46011 and 46054. ASCAT has the lowest bias in wind direction and the second lowest RMSE at 46028. WIND Toolkit has the second lowest bias and the lowest RMSE at all three sites.

\section{Discussion and conclusion}

This study provides a comprehensive evaluation of near-surface 

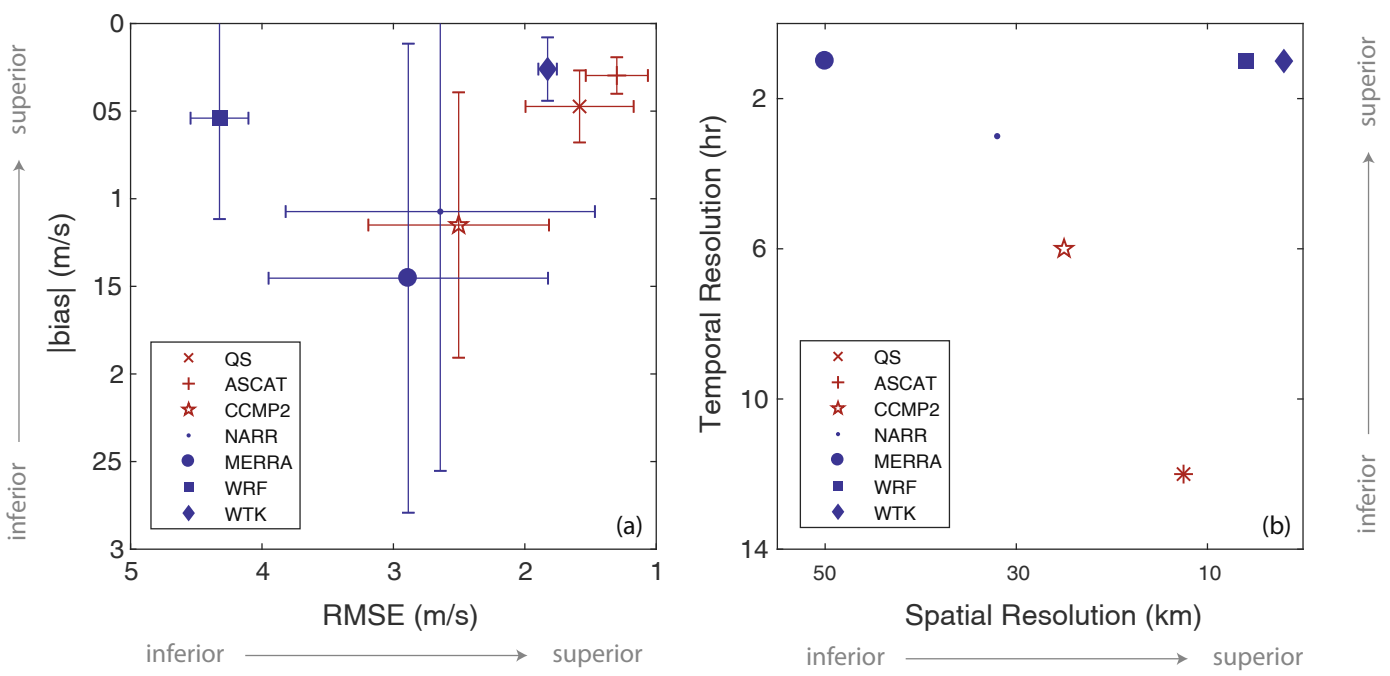

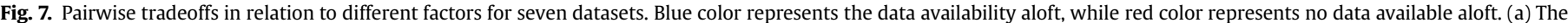

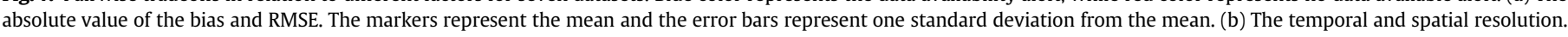

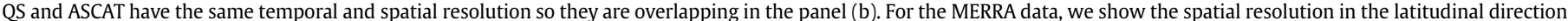
(see Table 1)

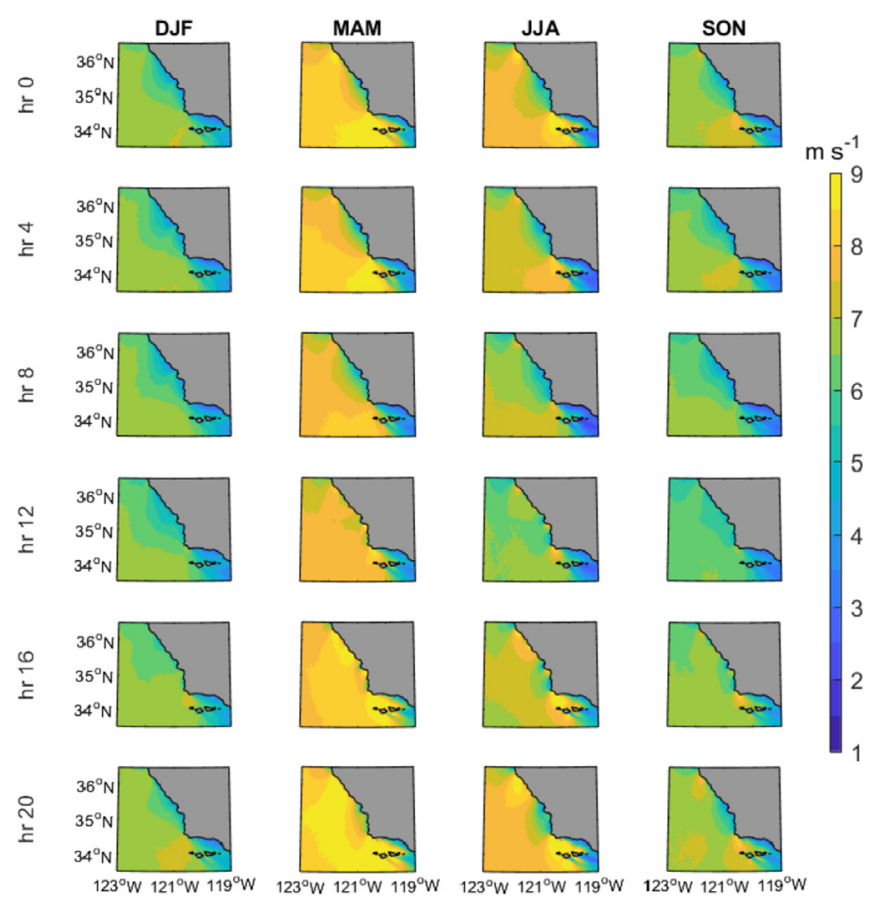

Fig. 8. Averages of the hourly 10-m wind speed from WIND Toolkit over 2007-2013 at different hours and four seasons. Each column from the left to the right represents winter (December-January-February, DJF), spring (March-April-May, MAM), summer (June-July-August, JJA), and fall (September-October-November, SON). Each row from the top to the bottom represents 00 PST, 04 PST, 08 PST, 12 PST, 16 PST, and 20 PST.

wind datasets along the central region of the California coast, ranging from south of Monterey Bay to north of Point Conception. This particular region has received considerable interest in the development of offshore wind farms due to its strong, steady winds and existing connections to the state's electrical grid. This study provides the first known assessment of various wind datasets in this region over both seasonal and diurnal time scales, both of which are critical for accurate assessment of offshore wind power production but are seldom considered at the same time by previous
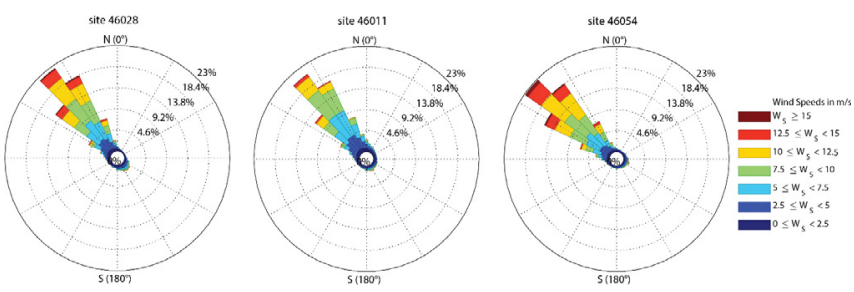

Fig. 9. Wind rose histograms using data from 1998 to 2016 for the three buoys considered in this study (46028, 46011, and 46054 from left to right, respectively). The direction shown is the direction from which the wind is coming from in degrees clockwise from true north (i.e., $0^{\circ}$ wind direction indicates a wind coming from the north and blowing to the south).

studies. In addition, this study provides a framework by which to assess spatiotemporal variations among various datasets for a particular region, including comparison of error metrics over both seasonal and diurnal time scales and tradeoff analysis. This framework can be applied to other regions - using the five factors we focused on and possibly others of importance - where accurate estimates of wind speed are needed to evaluate wind energy potential as well as other needs.

We examined near-surface wind fields from seven datasets, including satellite observations, reanalysis products, and regional model output. For each dataset considered, we found no common pattern of bias and RMSE at all local buoy sites on certain hours of the day or months of the year. Overall, the two scatterometers, QuikSCAT and ASCAT, showed the best performance relative to the in-situ buoy measurements. However, the coarse temporal resolution (i.e., two measurements per day) and spatial resolution $(12.5 \mathrm{~km})$ of these datasets limits their applicability for offshore wind power assessment, particularly since this region experiences strong diurnal wind forcing and strong spatial gradients in the wind field. On the other hand, WIND Toolkit was one of the most highly resolved datasets ( $1 \mathrm{~h}$ temporal and $2 \mathrm{~km}$ spatial resolution), and performed nearly as well as the scatterometers in the various error metrics we assessed. Moreover, the WIND Toolkit has wind data available above the surface and at potential turbine hub heights, which could obviate interpolation and extrapolation techniques needed with other data products [3]. Site-specific assessments 
should consider tradeoffs between spatiotemporal resolution of the underlying dataset, error metrics relative to local buoy measurements, and the availability of data at hub height when assessing various data products for offshore wind energy assessments and power calculations. With consideration of these factors, the WIND Toolkit appears to the best dataset for the central California region. Due to the lack of wind observations at altitudes greater than 5 or $10 \mathrm{~m}$ in this region, it is challenging to evaluate offshore wind power potential at hub height (i.e., heights of at least $100 \mathrm{~m}$ above the sea surface based on current technologies), which is a critical factor considered for future offshore wind siting and development. Since the surface wind distribution can provide the implications for wind distribution at hub height, future work will focus on the calculation of wind power generation at hub height from the WIND Toolkit under different scenarios both spatially and temporally.

Finally, tradeoff analysis is a useful graphical tool for comparing the relative performance of a set of options in relation to multiple objectives. Grounded in Portfolio Theory (maximize return, minimize risk of financial investments [40]), we applied tradeoff analysis to factors important to offshore wind power applications. This analysis revealed the overall superior value of WIND Toolkit (in relation to the prescribed factors), and more generally demonstrated a framework that could be used for evaluating wind datasets in other regions. Furthermore, the tradeoff analysis framework is adaptable, allowing for integration of additional factors important to offshore wind power applications, including potential impacts of wind energy development on the marine ecosystem [41,42]. In such cases the tradeoff analysis axes can be expanded to include these factors, and relative weights can be applied to the factors, in order to help identify development options that most effectively represent the socio-economic priorities in the system [43].

\section{Acknowledgements}

Study collaboration and funding were provided by the U.S. Department of the Interior, Bureau of Ocean Energy Management, Environmental Studies Program, Washington, DC under Agreement Number \#M16AC00023. Data used in this study are publically available at the respective links in the manuscript. The WRF regional model data were obtained from Dong et al. [44].

\section{References}

[1] I. Graabak, M. Korpås, Variability characteristics of European wind and solar power resources-a review, Energies 9 (2016) 449, https://doi.org/10.3390/ en9060449.

[2] X. Sun, D. Huang, G. Wu, The current state of offshore wind energy technology development, Energy 41 (2012) 298-312, https://doi.org/10.1016/ j.energy.2012.02.054.

[3] D. Carvalho, A. Rocha, M. Gómez-Gesteira, C. Silva Santos, Offshore winds and wind energy production estimates derived from ASCAT, OSCAT, numerical weather prediction models and buoys - a comparative study for the Iberian Peninsula Atlantic coast, Renew. Energy 102 (2017) 433-444, https://doi.org/ 10.1016/j.renene.2016.10.063.

[4] W.T. Liu, X. Xie, Measuring ocean surface wind from space, Remote Sens. Mar. Environ. Man. 6 (2006) 149-178.

[5] D. Carvalho, A. Rocha, M. Gómez-Gesteira, C. Santos, A sensitivity study of the WRF model in wind simulation for an area of high wind energy, Environ. Model. Software 33 (2012) 23-34, https://doi.org/10.1016/ j.envsoft.2012.01.019.

[6] M.H. Pickett, W. Tang, L.K. Rosenfeld, C.H. Wash, QuikSCAT satellite comparisons with nearshore buoy wind data off the U.S. West Coast, J. Atmos. Ocean. Technol. 20 (2003) 1869-1879, https://doi.org/10.1175/1520-0426(2003) $020<1869$ :QSCWNB $>2.0 . C O ; 2$.

[7] W. Tang, W.T. Liu, B.W. Stiles, Evaluation of high-resolution ocean surface vector winds measured by QuikSCAT scatterometer in coastal regions, IEEE Trans. Geosci. Rem. Sens. 42 (2004) 1762-1769, https://doi.org/10.1109/ TGRS.2004.831685.

[8] D. Carvalho, A. Rocha, M. Gómez-Gesteira, C. Silva Santos, Comparison of reanalyzed, analyzed, satellite-retrieved and NWP modelled winds with buoy data along the Iberian Peninsula coast, Remote Sens. Environ. 152 (2014) 480-492, https://doi.org/10.1016/j.rse.2014.07.017.

[9] I. Alvarez, M. Gomez-Gesteira, M. deCastro, D. Carvalho, Comparison of different wind products and buoy wind data with seasonality and interannual climate variability in the southern Bay of Biscay (2000-2009), Deep. Res. Part Il Top. Stud. Oceanogr. 106 (2014) 38-48, https://doi.org/10.1016/ j.dsr2.2013.09.028.

[10] E. Sharp, P. Dodds, M. Barrett, C. Spataru, Evaluating the accuracy of CFSR reanalysis hourly wind speed forecasts for the UK, using in situ measurements and geographical information, Renew. Energy 77 (2015) 527-538, https:// doi.org/10.1016/j.renene.2014.12.025.

[11] P. Beiter, W. Musial, A. Smith, R. Damiani, M. Maness, T. Stehly, V. Gevorgian, M. Mooney, G. Scott, P. Beiter, W. Musial, A. Smith, L. Kilcher, R. Damiani, M. Maness, S. Sirnivas, T. Stehly, A Spatial-economic Cost- Reduction Pathway Analysis for U. S. Offshore Wind Energy Development from 2015 - 2030 a Spatial-economic Cost- Reduction Pathway Analysis for U. S. Offshore Wind Energy Development from 2015 - 2030, 2016.

[12] W. Musial, D. Heimiller, P. Beiter, G. Scott, C. Draxl, 2016 Offshore Wind Energy Resource Assessment for the United States, 2016. NREL/TP-5000-66599.

[13] M.R. Fewings, L. Washburn, C.E. Dorman, C. Gotschalk, K. Lombardo, Synoptic forcing of wind relaxations at Pt. Conception, California, J. Geophys. Res. Ocean 121 (2016) 5711-5730, https://doi.org/10.1002/2016JC011699.

[14] Q. Jiang, J.D. Doyle, T. Haack, M.J. Dvorak, C.L. Archer, M.Z. Jacobson, Exploring wind energy potential off the California coast, Geophys. Res. Lett. 35 (2008) 1-6, https://doi.org/10.1029/2008GL034674.

[15] R.K. Walter, K.J. Armenta, B. Shearer, I. Robbins, J. Steinbeck, Coastal upwelling seasonality and variability of temperature and chlorophyll in a small coastal embayment, Cont. Shelf Res. 154 (2018) 9-18, https://doi.org/10.1016/ j.csr.2018.01.002.

[16] S. Pensieri, R. Bozzano, M.E. Schiano, Comparison between QuikSCAT and buoy wind data in the Ligurian sea, J. Mar. Syst. 81 (2010) 286-296, https:// doi.org/10.1016/j.jmarsys.2010.01.004.

[17] P.K. Taylor, E.C. Kent, M.J. Yelland, B.I. Moat, The accuracy of marine surface winds from ships and buoys, CLIMAR 99, WMO Work, Adv. Mar. Climatol. (1999) 59-68.

[18] W.T. Liu, W. Tang, Equivalent Neutral Wind, JPL Publ., 1996, pp. 17-96.

[19] S.B. Capps, C.S. Zender, Global ocean wind power sensitivity to surface layer stability, Geophys. Res. Lett. 36 (2009) 1-5, https://doi.org/10.1029/ 2008GL037063.

[20] A. Verhoef, A. Stoffelen, Validation of ASCAT 12. 5-km Winds, 2009, pp. 1-11.

[21] N. Ebuchi, H.C. Graber, M.J. Caruso, Evaluation of wind vectors observed by QuikSCAT/SeaWinds using ocean buoy data, J. Atmos. Ocean. Technol. 19 (2002) 2049-2062, https://doi.org/10.1109/IGARSS.2001.976753.

[22] Physical Oceanography Distributed Active Archive Center ( PO DAAC) QuikSCAT Level 2B Version 3 Guide Document. Version 17 March, 2013 pp. $1-16$.

[23] A. Bentamy, D. Croize-Fillon, C. Perigaud, Characterization of ASCAT measurements based on buoy and QuikSCAT wind vector observations, Ocean Sci. 4 (2008) 265-274, https://doi.org/10.5194/os-4-265-2008.

[24] D.E. Weissman, M.A. Bourassa, J. Tongue, Effects of rain rate and wind magnitude on SeaWinds scatterometer wind speed errors, J. Atmos. Ocean. Technol. 19 (2002) 738-746, https://doi.org/10.1175/1520-0426(2002) $019<0738$ :EORRAW $>2.0$. CO;2.

[25] S. Kako, A. Isobe, M. Kubota, High-resolution ASCAT wind vector data set gridded by applying an optimum interpolation method to the global ocean, J. Geophys. Res. Atmos. 116 (2011) 1-16, https://doi.org/10.1029/ 2010JD015484.

[26] G. Osi, EUMETSAT Advanced Retransmission Service ASCAT Wind Product User Manual, 2016, pp. 1-23.

[27] R. Atlas, R.N. Hoffman, J. Ardizzone, S.M. Leidner, J.C. Jusem, D.K. Smith D. Gombos, A cross-calibrated, multiplatform ocean surface wind velocity product for meteorological and oceanographic applications, Bull. Am. Meteorol. Soc. 92 (2011) 157-174, https://doi.org/10.1175/2010BAMS2946.1.

[28] M.M. Rienecker, M.J. Suarez, R. Gelaro, R. Todling, J. Bacmeister, E. Liu, M.G. Bosilovich, S.D. Schubert, L. Takacs, G.K. Kim, S. Bloom, J. Chen, D. Collins, A. Conaty, A. Da Silva, W. Gu, J. Joiner, R.D. Koster, R. Lucchesi, A. Molod, T. Owens, S. Pawson, P. Pegion, C.R. Redder, R. Reichle, F.R. Robertson, A.G. Ruddick, M. Sienkiewicz, J. Woollen, MERRA: NASA's modern-era retrospective analysis for research and applications, J. Clim. 24 (2011) 3624-3648, https://doi.org/10.1175/JCLI-D-11-00015.1.

[29] F. Mesinger, G. DiMego, E. Kalnay, K. Mitchell, P.C. Shafran, W. Ebisuzaki, D. Jović, J. Woollen, E. Rogers, E.H. Berbery, M.B. Ek, Y. Fan, R. Grumbine, W. Higgins, H. Li, Y. Lin, G. Manikin, D. Parrish, W. Shi, North American regional reanalysis, Bull. Am. Meteorol. Soc. 87 (2006) 343-360, https:// doi.org/10.1175/BAMS-87-3-343.

[30] C. Draxl, A. Clifton, B.M. Hodge, J. McCaa, The wind integration national dataset (WIND) toolkit, Appl. Energy 151 (2015) 355-366, https://doi.org/ 10.1016/j.apenergy.2015.03.121.

[31] B. Bylhouwer, D. Ianson, K. Kohfeld, Changes in the onset and intensity of wind-driven upwelling and downwelling along the North American Pacific coast, J. Geophys. Res. Ocean 118 (2013) 2565-2580, https://doi.org/10.1002/ jgrc.20194.

[32] X. Li, S. Zhong, X. Bian, W.E. Heilman, Climate and climate variability of the wind power resources in the Great Lakes region of the United States, J. Geophys. Res. Atmos. 115 (2010) 1-15, https://doi.org/10.1029/ 
2009JD013415.

[33] G.W.K. Moore, R.S. Pickart, I.A. Renfrew, Buoy observations from the windiest location in the world ocean, Cape Farewell, Greenland, Geophys. Res. Lett. 35 (2008) 3-7, https://doi.org/10.1029/2008GL034845.

[34] W.C. Skamarock, J.B. Klemp, J. Dudhi, D.O. Gill, D.M. Barker, M.G. Duda, X.Y. Huang, W. Wang, J.G. Powers, A description of the advanced research WRF version 3, Tech. Rep. (2008) 113, https://doi.org/10.5065/D6DZ069T.

[35] L. Renault, A. Hall, J.C. McWilliams, Orographic shaping of US West Coast wind profiles during the upwelling season, Clim. Dynam. 46 (2016) 273-289, https://doi.org/10.1007/s00382-015-2583-4.

[36] M. Nakanishi, H. Niino, An improved Mellor-Yamada Level-3 model: its numerical stability and application to a regional prediction of advection fog Boundary-Layer Meteorol. 119 (2006) 397-407, https://doi.org/10.1007 s10546-005-9030-8.

[37] C. Draxl, B. Hodge, A. Clifton, C. Draxl, B. Hodge, A. Clifton, Overview and Meteorological Validation of the Wind Integration National Dataset Toolkit, 2015, pp. 1-87. NREL/TP-5000-61740.

[38] S.E. Lester, C. Costello, B.S. Halpern, S.D. Gaines, C. White, J.A. Barth, Evaluating tradeoffs among ecosystem services to inform marine spatial planning, Mar. Pol. 38 (2013) 80-89, https://doi.org/10.1016/j.marpol.2012.05.022.

[39] R.K. Walter, E.C. Reid, K.A. Davis, K.J. Armenta, K. Merhoff, N.J. Nidzieko, Loca diurnal wind-driven variability and upwelling in a small coastal embayment, J. Geophys. Res. Ocean 122 (2017) 955-972, https://doi.org/10.1002/ 2016JC012466.

[40] H. Markowitz, Portfolio selection, J. Finance 7 (1952) 77-91, https://doi.org/ 10.1111/j.1540-6261.1952.tb01525.x.
[41] C. White, B.S. Halpern, C.V. Kappel, Ecosystem service tradeoff analysis reveals the value of marine spatial planning for multiple ocean uses, Proc. Natl. Acad. Sci. U. S. A. 109 (2012) 4696-4701, https://doi.org/10.1073/ pnas.1114215109/-/DCSupplemental. Www.pnas.org/cgi/doi/10.1073/pnas. 1114215109.

[42] H. Farr, Y. Wang, B. Ruttenberg, R. Walter, C. White, Environmental Impacts of Deepwater Floating Offshore Wind and Wave Energy Facilities, Western Society of Naturalists, Pasadena, CA, November 2017.

[43] S.E. Lester, J.M. Stevens, R.R. Gentry, C.V. Kappel, T.W. Bell, C.J. Costello S.D. Gaines, D.A. Kiefer, C.C. Maue, J.E. Rensel, R.D. Simons, L. Washburn, C. White, Marine spatial planning makes room for offshore aquaculture in crowded coastal waters, Nat. Commun. 9 (2018) 945, https://doi.org/10.1038/ s41467-018-03249-1.

[44] C. Dong, L. Renault, Y. Zhang, J. Ma, Y. Cao, Expansion of West Coast Oceanographic Modeling Capability, US Department of the Interior, Bureau of Ocean Energy Management, Pacific, 2017, p. 83. OCS Study BOEM 2017-055, https:// www.boem.gov/espis/5/5636.pdf.

[45] Prachi Patel, Floating Wind Turbines to Be Tested, IEEE Spectrum, 2009. Retrieved from, https://spectrum.iee.org/green-tech/wind/floating-windturbines-to-be-tested, 30 July 2018.

[46] J. Frith, The World's First Floating Wind Farm, Statoil's Hywind Project, Has Been Officially Opened by Scotland's First Minister Nicola Sturgeon, Maritime Journal, 2017. Retrieved from, http://www.maritimejournal.com/news101/ marine-renewable-energy/words-first-floating-offshore-wind-farm-nowopen, 2 March 2018 